\title{
PENGEMBANGAN AGROWISATA BERBASIS PERTANIAN SAYURAN ORGANIK DI DESA ANTAPAN KECAMATAN BATURITI KABUPATEN TABANAN BALI
}

\author{
N.M.S. Sukmawati ${ }^{1}$, N.W. Suniti ${ }^{2}$, dan I.N. Sujana ${ }^{3}$
}

\begin{abstract}
ABSTRAK
Desa Antapan adalah sebuah desa yang sebagian besar penduduknya bermatapencaharian sebagai petani sayuran. Lokasi desa yang berdekatan dengan objek wisata Bedugul dan memiliki panorama yang indah membuat desa ini sangat potensial untuk dikembangkan menjadi agrowisata. Tujuan dari pengembangan agrowisata ini adalah untuk meningkatkan pendapatan dan kesejahteraan masyarakat karena selama ini harga sayuran tidak menentu dan tergantung pada pengepul. Beberapa permasalahan yang dihadapi dalam pengembangan agrowisata di Desa Antapan adalah kurangnya pengetahuan mayarakat dalam menyiapkan agrowisata seperti paket wisata, pemandu wisatawan, dan pemasaran. Metode yang digunakan dalam kegiatan ini adalah Partisipatory Rural Appraisal (PRA), Entrepreneurship Capacity Building (ECB), Technology Transfer (TT) dan pendampingan. Dari program pengabdian masyarakat ini sudah terbentuk agrowisata yang bernama "Mayungan Agrowisata" karena lokasinya di Dusun Mayungan, Desa Antapan. Agrowisata ini dikelola oleh kelompok wisata yang berfungsi sebagai tenaga dan pemandu yang berjumlah 20 orang dari masyarakat setempat. Untuk mendukung kegiatan agrowisata ini telah dilaksanakan pelatihan pokdarwis dan pengolahan produk pertanian setempat. Paket wisata yang dibuat adalah ekowisata, masak, out born dan tracking menuju air terjun. Selain paket wisata juga disediakan oleh-oleh khas Desa Antapan. Dari kegiatan ini dapat disimpulkan bahwa program ini berjalan lancar dan sangat bermanfaat bagi masyarakat setempat.
\end{abstract}

Kata kunci : Agrowisata, sayuran sehat, Antapan

\begin{abstract}
Antapan is one of the village that located at Baturiti subdistrict, Tabanan regency. Most of the people in this village is as a vegetable farmer. The location of this village is near to the Bedugul sights, so it is potential to be developed into agrotourism. The purpose of this agrotourism development is to increase the income and welfare of the community because during this time the vegetable prices are erratic and dependent on the pintards. Some of the problems in the development of Agrotourism in Antapan village is the lack of knowledge in preparing agro-tourism such as tour packages, tourist guides, brochure preparation, and marketing. The methods used in this activity are : Partisipatory Rural Appraisal (PRA), Entrepreneurship Capacity Building (ECB), Technology Transfer (TT) and mentoring. From this program of community devotion already formed agro tourism named "Mayungan Agrowisata" because its location in Dusun Mayungan, Antapan village. This agrotourism is managed by a tourism group that serves as a worker and guide that amounted to 20 people from the local community. The tour packages are : eco tourism, cooking package, tent package and tracking to waterfall. In addition to tour packages are also provided souvenirs typical of Antapan village. From this programe it can be conclouded that agrotourism development is benefit to the local community.
\end{abstract}

\footnotetext{
${ }^{1}$ Fakultas Peternakan, Universitas Udayana, sucisukma@unud.ac.id

${ }^{2}$ Program Studi Agroekoteknologi Fakultas Pertanian Universitas Udayana, sunitiwayan@gmail.com

${ }^{3}$ Program Studi Sastra Indonesia Fakultas Sastra Universitas Dwijendra
} 
Keywords: agrotourism, healthy vegetables, Antapan

\section{PENDAHULUAN}

Desa Antapan adalah salah satu desa yang terletak di Kecamatan Baturiti Kabupaten Tabanan, Bali. Desa ini terletak pada ketinggian $800 \mathrm{~m}$ dpl dengan kondisi wilayah yang berbukit-bukit serta memiliki suhu udara yang dingin. Dengan topografi tersebut membuat desa Antapan memiliki panorama yang indah dan terlihat jelas hamparan di kaki gunung Batukaru. Dari kejauhan juga tampak gunung Agung dan gunung Batur. Selain panorama pegunungan yang berjejer disisi barat dan timur, di sana juga terdapat beberapa lokasi air terjun yang belum dikelola dengan baik.

Matapencaharian penduduk di desa Antapan dan sekitarnya adalah sebagai petani holtikultura (sayur-sayuran) sehingga dalam RPJM kabupaten Tabanan ditetapkan sebagai sentra pengembangan tanaman holtikultura. Jenis sayuran yang diusahakan diantaranya kubis, caisin, selada, tomat, kentang, wortel, dan lain-lain. Kegiatan usaha tani yang intensif telah mendorong pemakaian pupuk anorganik terus meningkat demikian juga pestisida sehingga menimbulkan pencemaran lingkungan dan berdampak negatif terhadap tanah, organisme yang hidup di dalam tanah, dan manusia yang mengkonsumsi produk holtikultura tersebut.

Dalam upaya mengurangi penggunaan pestisida maka program kemitraan wilayah ini mengajak petani untuk kembali ke pertanian organik dan mengemasnya dalam bentuk agrowisata sayuran organik yang dipadukan dengan potensi wilayah yang ada seperti air terjun. Potensi agrowisata Desa Antapan didukung pula oleh lokasi geografisnya yang sangat strategis yaitu berdekatan dengan objek wisata Bedugul yang telah dikenal luas baik oleh wisatawan lokal maupun mancanegara. Untuk itu, pemberdayaan masyarakat tani melalui pengembangan wawasan agribisnis dan agrowisata dengan tetap dalam bingkai tatanan budaya Bali sangat diperlukan. Ragam wisata yang dapat dikembangkan diantaranya pengembangan pertanian organik dan pengemasan aktivitas panen produk setempat yang dapat dinikmati langsung menjadi paket wisata. Paket agrowisata sayuran organik dipadukan dengan air terjun merupakan paket wisata yang sangat diminati oleh wisatawan yang sangat potensial bagi Desa Antapan.

Permasalahan yang dihadapi adalah lemahnya kemampuan sumber daya manusia (SDM) lokal dalam mengelola dan mengimplementasikan potensi agrowisata yang dimiliki, kurangnya kemampuan dalam mengemas paket agrowisata, kurangnya kesiapan sebagai pemandu wisata, lemahnya kemampuan bahasa asing, dan kurangnya keberanian untuk memulai kegiatan wisata. Di bidang pertanian, petani di Desa Antapan belum mampu menyediakan atraksi atau kegiatan yang dapat melibatkan wisatawan, baik dalam kegiatan kebun maupun di luar kebun. Petani dan masyarakat Desa Antapan belum mampu mengemas berbagai potensi yang dimiliki menjadi sesuatu yang dapat dilihat, sesuatu yang dapat dikerjakan, sesuatu yang dapat dibeli, dan sesuatu yang dapat diajari yang menarik bagi wisatawan. Oleh sebab itu, maka program ini sangat perlu dilaksanakan untuk meningkatkan pengetahuan dan ketrampilan masyarakat dalam bidang agrowisata.

\section{METODE PELAKSANAAN}

Berdasarkan permasalahan yang telah diuraikan di latar belakang, maka metode yang digunakan adalah penerapan model: (1) Partisipatory Rural Appraisal (PRA), (2) Entrepreneurship Capacity Building (ECB), (3) Technology Transfer (TT) dan pendampingan yaitu pertemuan secara berkala dan berkelanjutan antara pendamping dengan masyarakat sasaran hingga ipteks yang dialihkan 
dapat dilaksanakan secara mandiri oleh masyarakat. Metode PRA dilakukan melalui Focus Group Discussion ( $F G D$ ) difasilitasi oleh tim PKW dengan milibatkan tokoh-tokoh desa (desa dinas dan desa adat), karang taruna, kelompok tani, dan calon potensial pelaku agrowisata untuk mendapatkan rumusan potensi agrowisata yang cocok dikembangkan dalam rangka mengemas aktivitas paket agrowisata. Melalui metode ini sekaligus diharapkan dapat meningkatkan pemahaman dan kesiapan masyarakat tani dan masyarakat desa dalam kegiatan kepariwisataan, terutama dalam hal penentuan komponen kemasan paket agrowisata. Sedangkan metode ECB dan TT dilakukan untuk meningkatkan kemampuan dan kualitas SDM lokal dalam pengembangan agrowisata melalui kegiatan pelatihan mengkemas paket agrowisata dan paket tracking, pelatihan teknik memandu (guiding) agrowisata dan tracking, pelatihan bahasa inggris bagi calon pemandu lokal dan Karang Taruna.

\section{HASIL DAN PEMBAHASAN}

Agrowisata merupakan salah satu jenis wisata yang memanfaatkan usaha pertanian (agro) menjadi suatu objek wisata (Sutjipta, 2008). Pengertian ini mengacu pada unsur rekreatif yang memang sudah menjadi ciri kegiatan wisata, unsur pendidikan dalam kemasan paket wisatanya, serta unsur sosial ekonomi dalam pembangunan pertanian dan perdesaan. Dari segi substansinya kegiatan agrowisata lebih menitikberatkan pada upaya menampilkan kegiatan pertanian dan suasana perdesaan sebagai daya tarik utama wisatanya tanpa mengabaikan segi kenyamanan. Berdasarkan Surat Keputusan (SK) bersama antara Menteri Pariwisata, Pos dan Telekomunikasi dan Menteri Pertanian No. KM.47/PW.DOW/MPPT-89 dan No. 204/KPTS/HK/050/4/1989 agrowisata sebagai bagian dari objek wisata, diartikan sebagai suatu bentuk kegiatan yang memanfaatkan usaha agro sebagai objek wisata dengan tujuan untuk memperluas pengetahuan, pengalaman rekreasi dan hubungan usaha di bidang pertanian (Tirtawinata dan Fachruddin, 1996). Pengembangan agrowisata akan membangun komunikasi antara petani dengan wisatawan. Melalui pengembangan agrowisata yang menonjolkan budaya lokal dalam memanfaatkan lahan, pendapatan petani diharapkan dapat ditingkatkan dan sekaligus melestarikan sumber daya lahan, serta memelihara budaya maupun teknologi lokal yang umumnya sesuai dengan kondisi lingkungan alaminya (Sardiana and Purnawan, 2016; Sardiana dan Purnawan, 2015). Dengan adanya agrowisata, petani bisa lebih kreatif mengelola usaha taninya sehingga mampu menghasilkan produk yang menyentuh hati wisatawan. Bila hasil pertanian (buah, sayur, bunga, daging, dan ikan) bisa diserap oleh hotel dan restoran dengan harga yang memadai tentu akan sangat membantu peningkatan pendapatan petani (Sardiana, 2018; Purnawan dan Sardiana, 2018)

Desa Antapan yang mata pencaharian penduduknya sebagian besar sebagai petani sayuran (holtikultura), selama ini memasarkan produknya kepada pengepul dengan harga yang ditentukan oleh pembelinya. Pada saat produksi rendah, mereka bisa membeli dengan harga tinggi, namun disaat produksi melimpah harga langsung anjlok bahkan sering juga petani tidak memanen sayurnya karena tidak ada yang beli. Hal ini terjadi karena petani satu dengan lainnya memiliki kebiasaan menanam produk yang sama dalam jumlah banyak secara bersamaan sehingga kontinyuitasnya tidak bisa dijaga. Selain itu, pertanian yang dikembangkan di desa Antapan dilakukan secara intensif dengan menggunakan bahan-bahan kimia sehingga berdampak negatif terhadap lingkungan. Melalui program kemitraan wilayah (PKW) sudah dilakukan upaya untuk mengajak petani kembali ke pertanian organik. Langkah awal yang dilakukan adalah memberikan pengetahuan kepada petani tentang bahaya penggunaan bahan-bahan kimia terhadap kesehatan dan lingkungan. Selanjutnya melatih pembuatan pupuk organik padat dan cair langsung dengan aplikasinya di lapangan. Tahap terakhir adalah dengan mengembangkannya menjadi agrowisata agar memiliki nilai jual yang lebih tinggi. Agrowisata sayuran ini mulai dikerjakan tanggal 25 Juni 2019 di sela-sela kesibukan masyarakat yang padat dengan upacara adat. Proses pengerjaan lahan dan pelatihan pokdarwis sebagai penunjang agrowisata ini ditampilkan pada Gambar 1. 
Agrowisata ini dirancang sedemikian rupa sehingga pengunjung merasa berkesan dan ingin kembali datang di kemudian hari. Di lokasi ini juga disediakan tempat berfoto (selfi) sesuai dengan perkembangan saat ini. Beberapa paket wisata yang disediakan antara lain : ekowisata; nanam dan panen sayur; paket memasak, dan out born. Agrowisata ini juga dipadukan dengan jalur tracking menuju air terjun yang lokasinya berdekatan dengan kebun sayur. Selesai mengunjungi air terjun, wisatawan bisa menikmati kuliner yang disediakan di lokasi agrowisata sayuran. Untuk oleh-oleh , pengunjung bisa membeli sayuran, bibit sayur dan bunga serta produk-produk olahan hasil pertanian setempat.

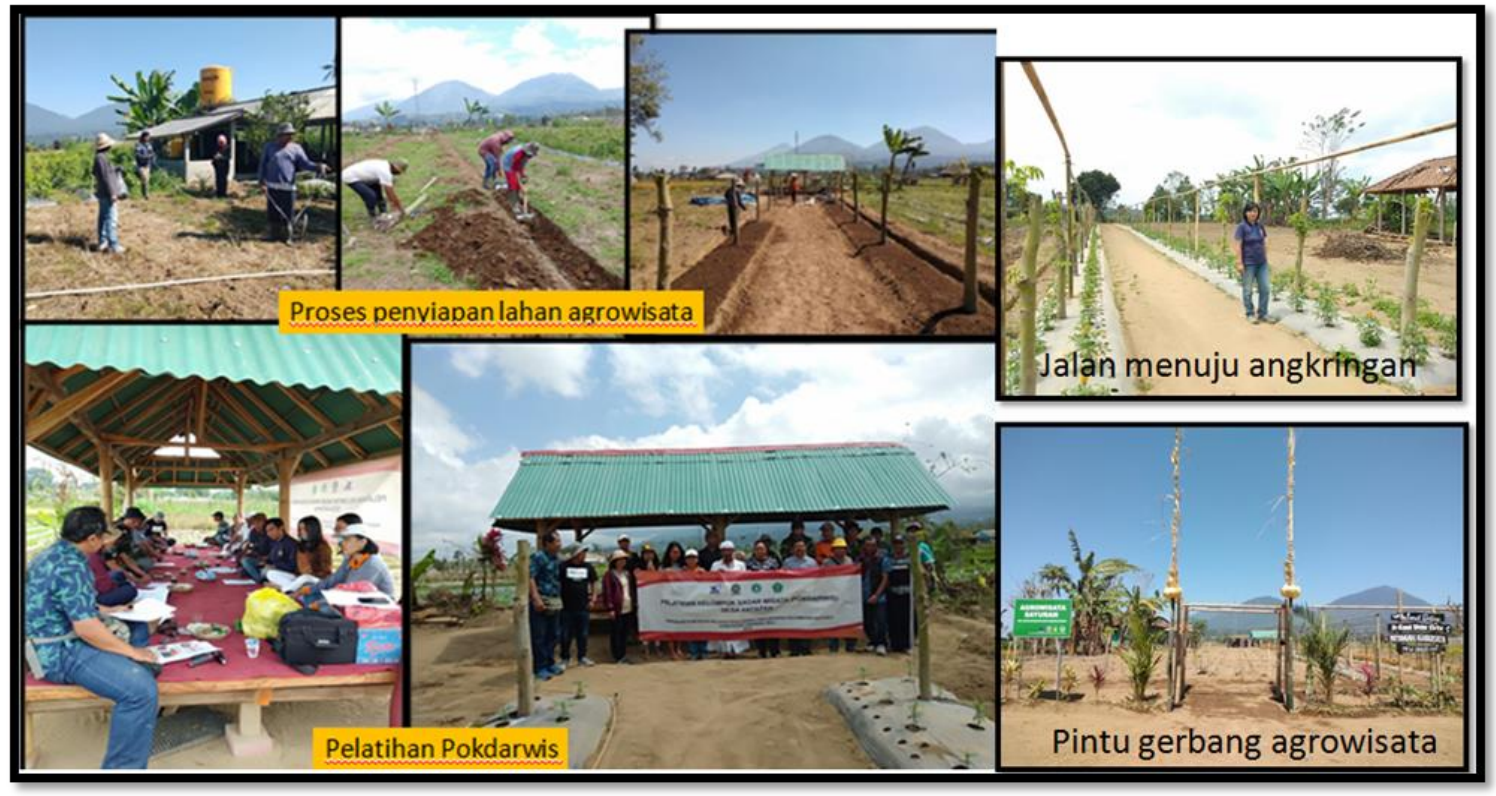

Gambar 1. Proses pengembangan Agrowisata di Desa Antapan

Untuk menunjang agrowisata ini agar bisa berjalan lancar, perlu beberapa persiapan terlebih dahulu seperti pembuatan sarana dan prasarana di lokasi agro dan pelatihan sumber daya manusia yang menjalankan usaha agro tersebut. Hal-hal yang dilakukan antara lain : pembentukan kelompok wisata sebagai pengelola agrowisata, pelatihan sebagai pemandu wisata, pelatihan pengolahan produk pertanian setempat sampai pengemasan dan pemasaran dan pembuatan paket wisata. Kegiatan wisata yang sudah dilaksanakan ditampilkan pada Gambar 2.

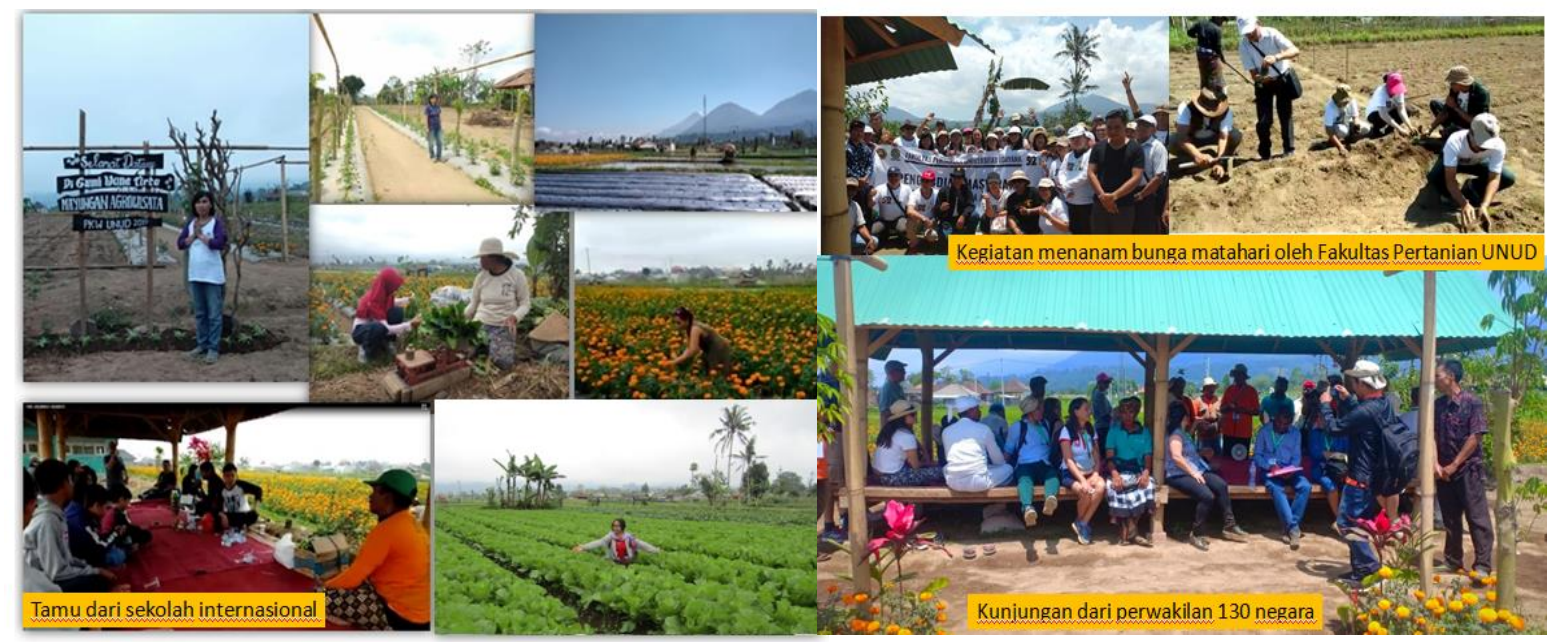


Gambar 2. Kegiatan wisata di Mayungan Agrowisata

Foto pada Gambar 2 merupakan kunjungan tamu pertama dari sekolah internasional yang melaksanakan perkemahan selama dua hari satu malam pada hari sabtu dan minggu. Mereka diajak berkeliling di sekitar kebun dan rumah penduduk untuk melihat situasi desa Antapan yang dipandu oleh anak-anak muda desa setempat. Pada gambar tersebut juga terlihat bahwa bapak ketua kelompok wisata sedang berbincang-bincang dengan anak-anak sekolah yang berkunjung, sementara orang tua siswa mengisi waktu dengan memetik bunga dan ada yang beli sayuran serta berfoto-foto di kebun sayur. Agrowisata ini terus akan dikembangkan dan ditata agar lebih menarik. Dari kesan yang disampaikan oleh orang tua murid yang berkunjung, mereka sangat senang dengan acara ini karena dapat menambah wawasan dan kemandirian anak-anak mereka. Manfaat yang didapatkan oleh anak-anak yang berkunjung di agrowisata ini sangat banyak, diantaranya mereka bisa mengenal lingkungan lebih luas terutama di bidang pertanian holtikultura, mengenal kehidupan masyarakat di desa, melatih kerjasama di dalam kelompok dan bisa merasakan kehidupan di alam bebas dengan fasilitas yang serba terbatas. Hal ini akan dapat merubah mental anak-anak secara perlahan-lahan. Kunjungan yang kedua adalah dari 50 dosen Fakultas Pertanian Unud dalam rangka kegiatan pengabdian masyarakat yang diisi dengan kegiatan menanam bunga matahari dan demo pembuatan minyak biji bunga matahari. Tamu ketiga adalah dari perwakilan 130 negara asing yang merupakan rangkaian kegiatan dari kementrian pertanian di lokasi Simantri 356 dan sistem pertanian bioindustri binaan BPTP Bali. Dari kesan beberapa pengunjung, menunjukkan bahwa mereka sangat senang dengan suasana di lokasi agrowisata ini dan akan kembali berkunjung di lain waktu. Hal ini menunjukkan bahwa agrowisata sayuran terpadu ini mempunyai peluang besar untuk dikembangkan.

\section{KESIMPULAN}

Pengembangan agrowisata di Desa Antapan berjalan lancar dan sangat bermanfaat bagi masyarakat. Keberhasilan ini terbukti dengan sudah adanya kunjungan dari anak-anak sekolah internasional yang melaksanakan kegiatan ekowisata selama dua hari walaupun agrowisata ini belum selesai seratus persen, kunjungan dari Fakultas Pertanian Unud dan perwakilan dari 130 negara asing.

\section{UCAPAN TERIMA KASIH}

Penulis mengucapkan terima kasih kepada Direktorat Riset dan Pengabdian kepada Masyarakat, Dirjen DIKTI melalui Lembaga Penelitian dan Pengabdian masyarakat Unud, dan Pemda Kabupaten Tabanan atas dana yang diberikan sehingga pengabdian masyarakat berjalan dengan baik. Penulis juga mengucapkan terima kasih yang sebesar-besarnya kepada Bapak I Wayan Widana selaku ketua kelompok "Setia Makmur" atas kerjasamanya sehingga kegiatan ini berjalan lancar.

\section{DAFTAR PUSTAKA}

Anon. 2015. Profil Pembangunan Desa Antapan, Kecamatan Baturiti Kabupaten Tabanan.

[BPS] Badan Pusat Statistik. 2015. Kecamatan Baturiti dalam Angka tahun 2015. Badan Statistik Kabupaten Tabanan

Sutjipta. 2008. Agribisnis Pembangunan Setengah Hati. Universitas Udayana. Denpasar

Tirtawinata, M.R. dan L. Fachruddin. 1996. Daya Tarik Dan Pengelolaan Agrowisata. Jakarta: Penebar Swadaya.

Purnawan, NLR., I.K Sardiana. 2017. Paket Wisata Edukasi Subak Upaya Menjaga Keberlanjutan Potensi Pertanian dan Pariwisata Berbasis Budaya di Bali. Jurnal Kawistara 7 (3), 275-284 
Sardiana, IK. 2018. The Study of Development of Urban Farming Agrotourism Subak-Irrigation-Based in Sanur Tourism Area, Denpasar City, Bali. Journal of Indonesian Tourism and Development Studies 6 (1), 33-40

Sardiana, IK., NLR Purnawan., 2016. Indigenous community, ecotourism and sustainability: Experience from Tenganan Dauh Tukad traditional. Heritage, Culture and Society: Research agenda and best practices in the hospitality and tourism ind | vol: | issue : |2016-01-01 | Conference Proceedin

Sardiana, IK., NLR Purnawan. 2015. Community-based Ecotourism in Tenganan Dauh Tukad: An Indigenous Conservation Perspective. Jurnal Kajian Bali (Journal of Bali Studies) 5 (2), 347-368 